\title{
حجية العقود المثبتة للملكية العقارية الخاصة في الأراضي غير الممسوحة في الجزائر
}

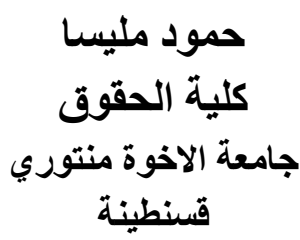

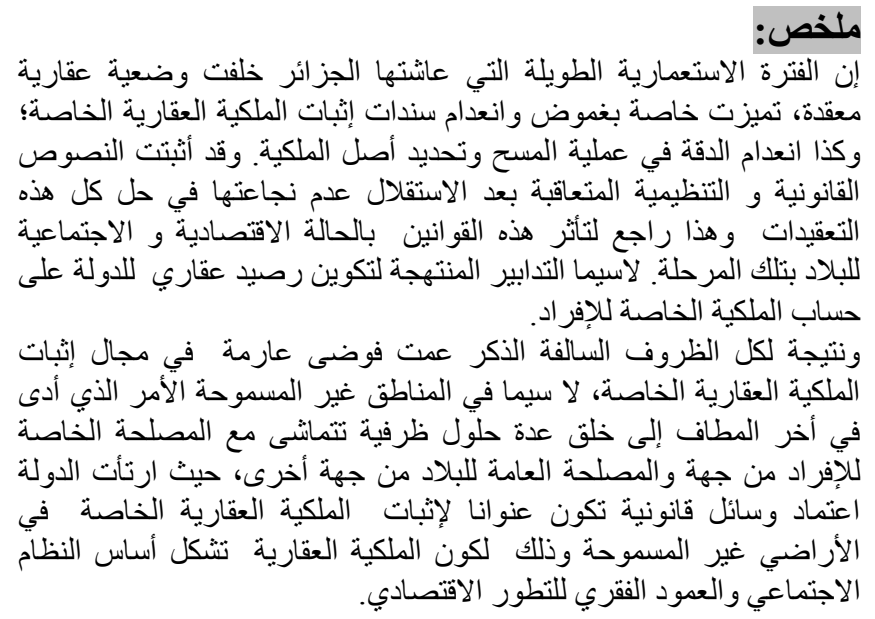

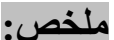

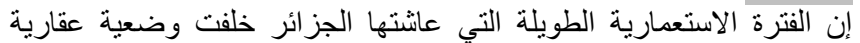

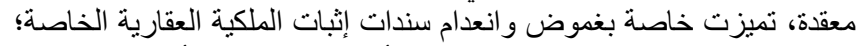

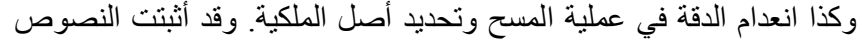

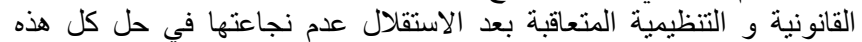

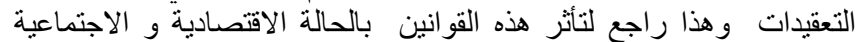

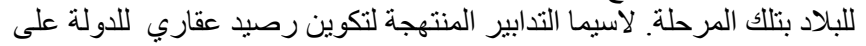

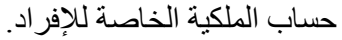

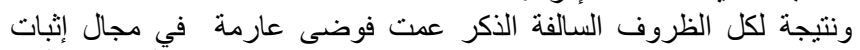

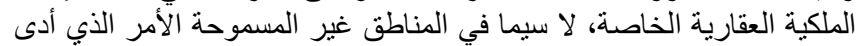

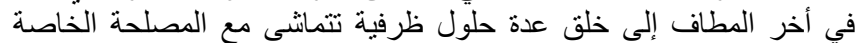

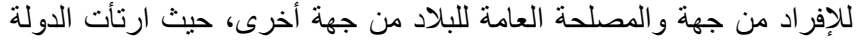

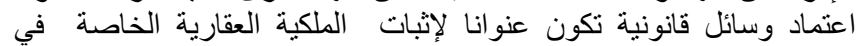

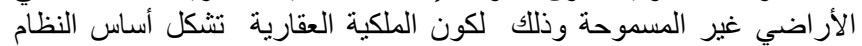
الاجتماعي والعمود الفقري للتطور الاقتصادي.

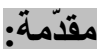

إن إنبة إثبات الملكية العقارية في الجزائر مرتبط ارتباطا وثيقا بمختلف المر احل التاريخية التي وني

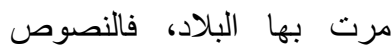

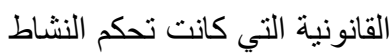

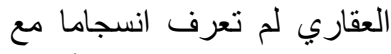

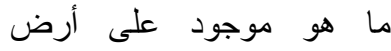

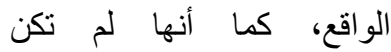
مضبوطة بصفة دقيقة وذللك

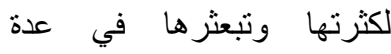

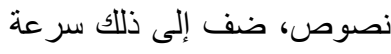

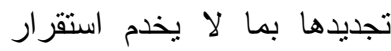

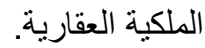

\begin{abstract}
:
The long colonial experienced by Algeria left behind it complex real estate condition, particularly characterized by ambiguous or nonexistent private property titles; and a lack of precision in operations of survey and identification of the origin of property. The consecutive legal and regulation texts that came after the independence had proven to be no efficient for resolving these complications, which is due to the impact of the economic and social situation of the country during that period. Particularly, the; reassures taken in order to constitute a real estate fund for the country at the expense of private property of individuals.

As a result of all the conditions aforementioned, chaos prevailed in the matter of establishment of private real estate, especially in unauthorized regions, wish at the end, led to the creation of many circumstantial conditions that were convenient to personal interest of individuals on one hand, and the main interests of the country on the other hand, in which the government decided to employ legal means that allows to establish private real estate property in unauthorized lands, as the real estate property constitutes the basis of social system and a pole of economic development.
\end{abstract}




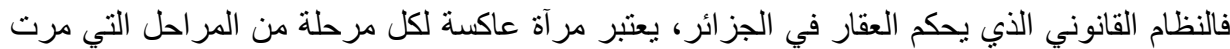

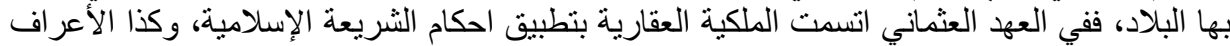

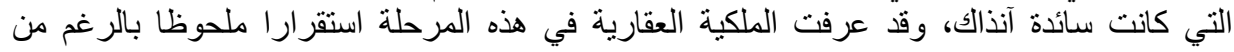

تنوعها.

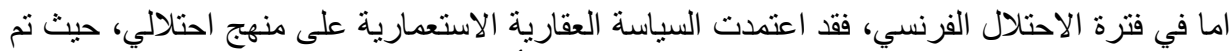

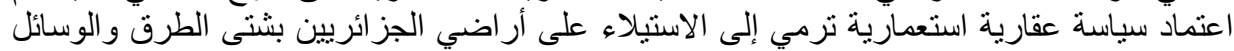

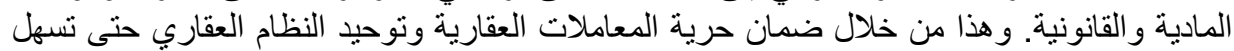

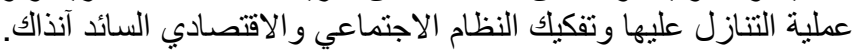

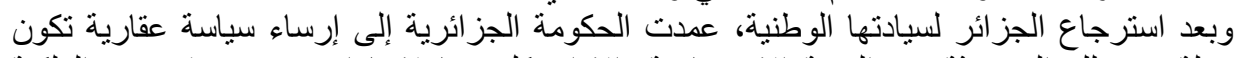

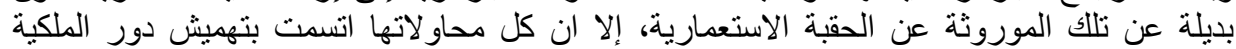

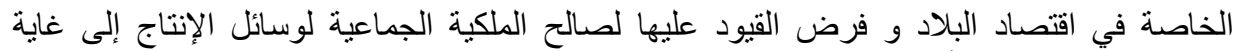

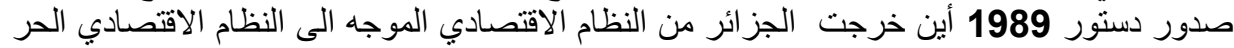

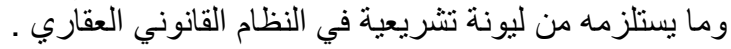

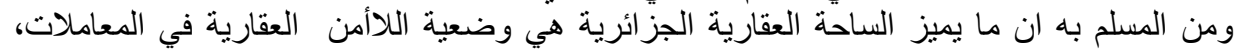

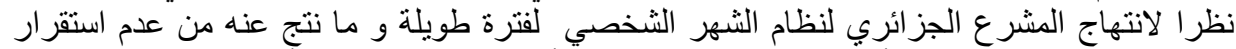

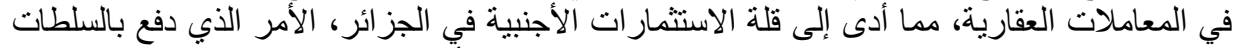

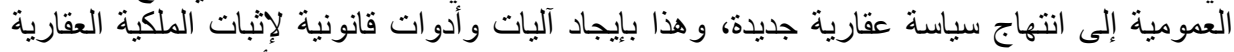

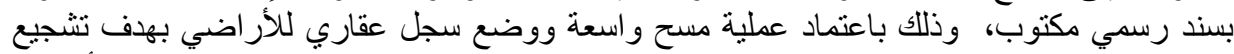

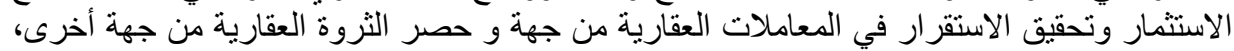

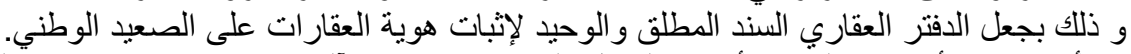

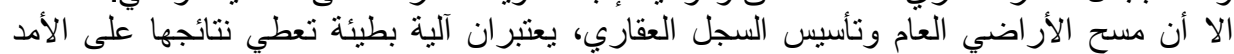

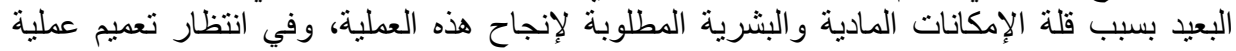

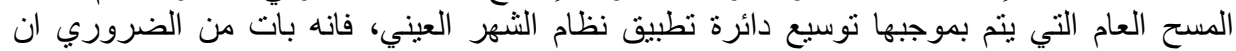

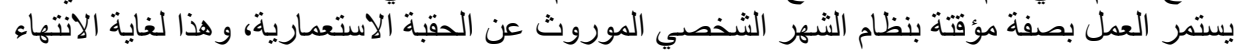
من عملية المسح على مجموع التراب الونه الوطني.

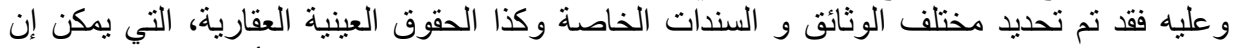

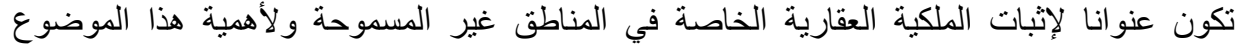

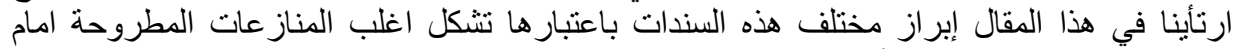

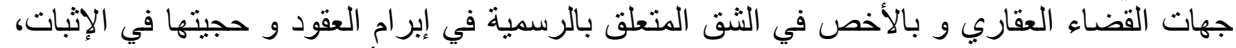

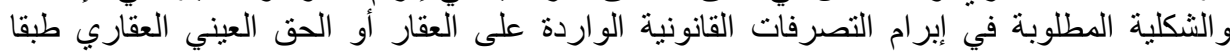

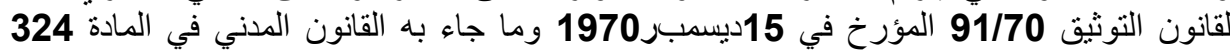
مكرر 1، وبالتالي فان لكل مرحلة زمنية وسائلها الخاصة في إثبات الملكية العقارية ابي قبل سنة الثانة

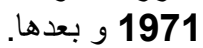

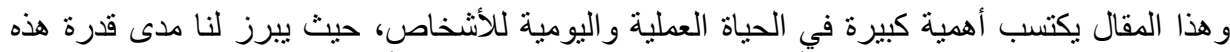

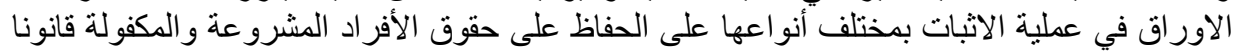

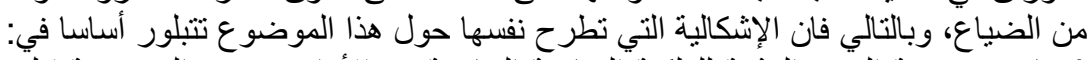

* ما مدى حجية العقود المثبتة للملكية العقارية الخاصة في الأراضي غير المبلية المسموحة قبل سنة 1971

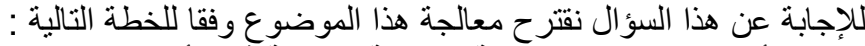

الفرع الأول: عقود إثبات الملكية العقارية الخاصة في الأراضي غير المغلة المسموحة قبل سنة 1971. * أولا: مفهوم العقود العرفية.

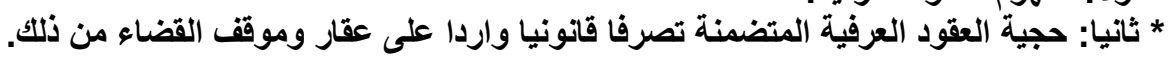




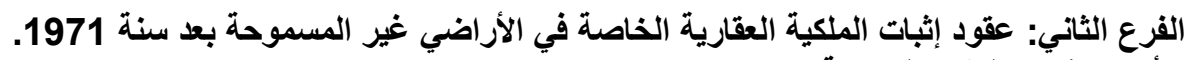
* أولا: مفهوم العقود الثرسمية. * ثانيا: حجية العقود الرسميةً المتضمنة تصرفا قانونيا واردا على عقار وموقف القضاءمن ذلك.

الفرع الأول: عقود اثبات الملكية العقارية الخاصة في الأراضي غير المسنموحة قبل سنة 1971 الإنة 1971

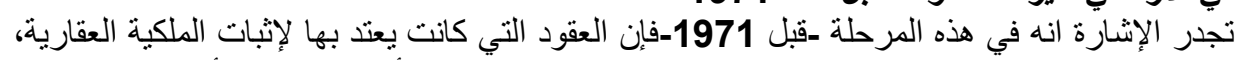

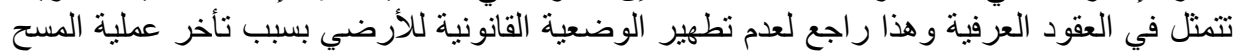

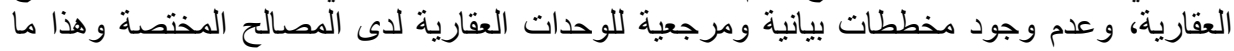

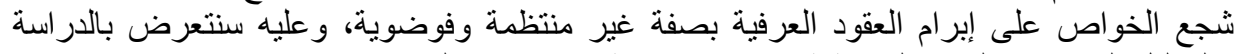
و التحليل إلى مفهوم العقود العرفية ثم حجيتها في الإثبات وموقف القئ القضاء منها.

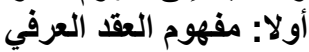

لتحديد مفهوم العقد العرفي لابد لنا من التطرق لمختلف التعاريف الخاصة به، وكذا تحديد شروط 1-تعريف العقد العرفي: نميز هنا بين التعريف القانوني والتعريف

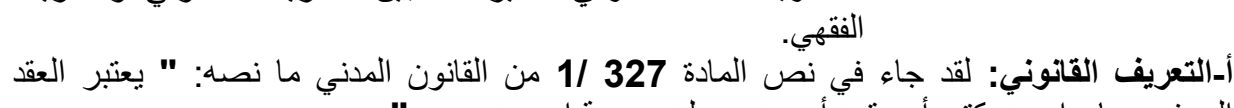

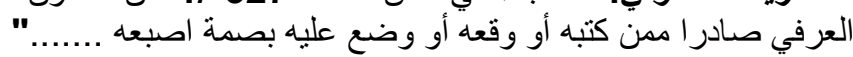

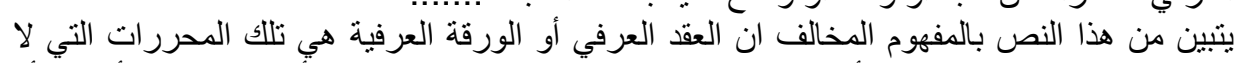

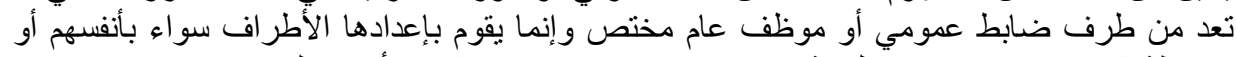

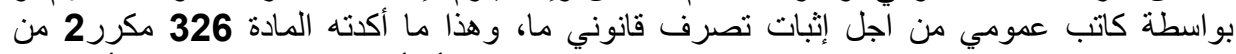

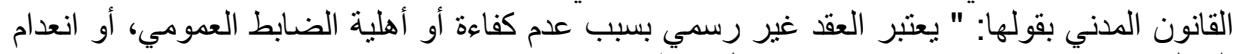

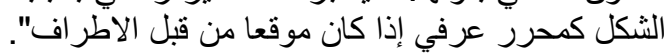
ب-التعريف الفقهي: لقد اختلفت التعاريف الفقية الفية للعقد العرفي وتعددت وأهمها:

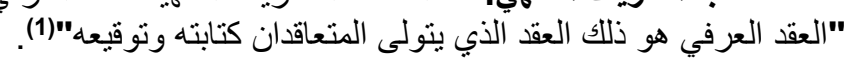

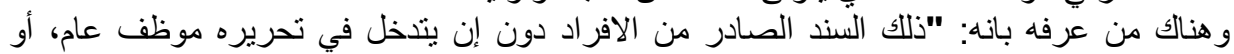

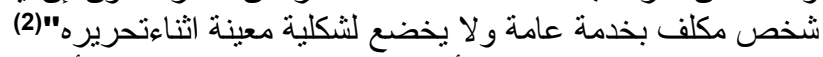

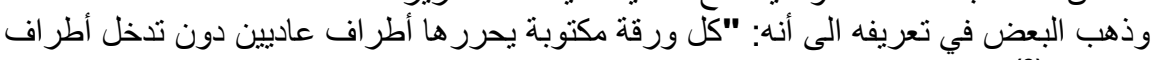

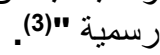
كما عرفه البعض الآخر بأنه:" تلك الأوراق التي تصدر من ذوي الثأن ويثبت فيها واقعة قانونية،

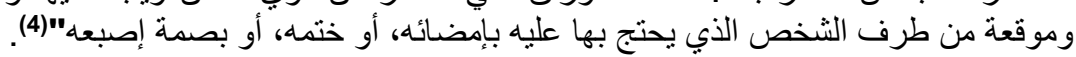

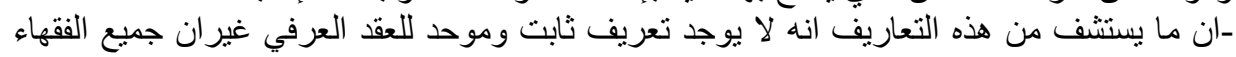

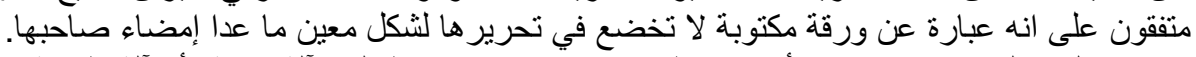

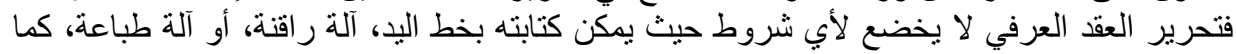

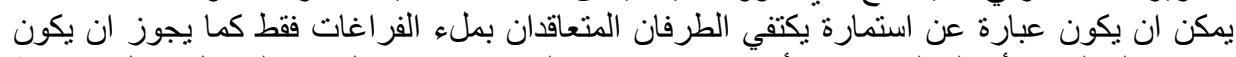

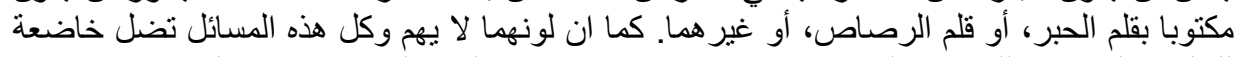

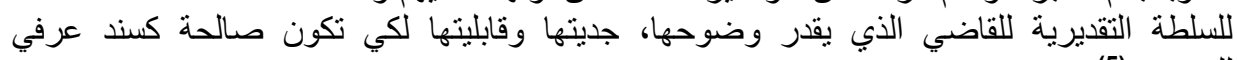

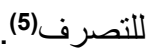

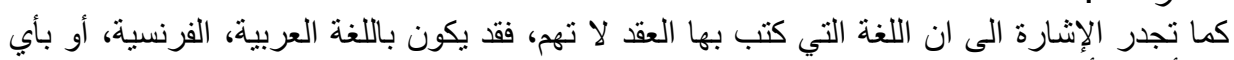

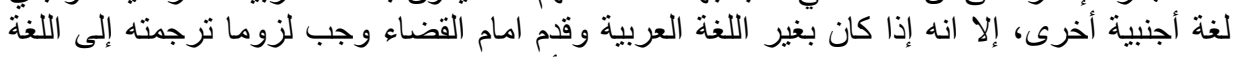

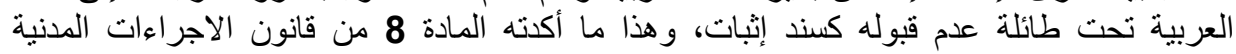


والإدارية(6) بقولها: "يجب إن تتم الإجر اءات والعقود القضائية من عرائض ومذكرات، باللغة العربية

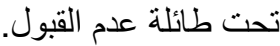

- يجب إن تقدم الوثائق و المستندات باللغة العربية او مصحوبة بترجمة رسمية الى هذه اللغة تحت

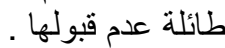

ـ ـتم المناقثات و والمر افعات باللغة العربية.

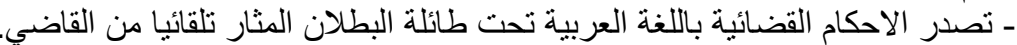

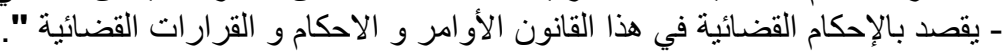

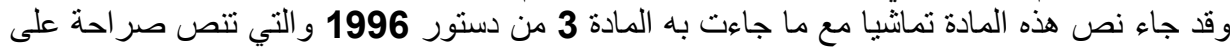
ان: "اللغة العربية هي اللغة الوطنية الرسمية".

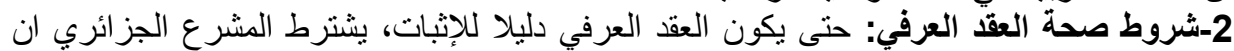

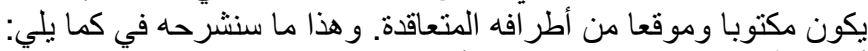

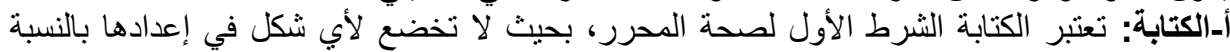

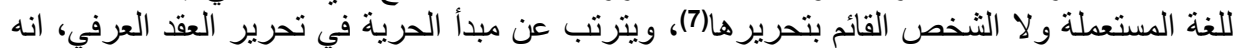

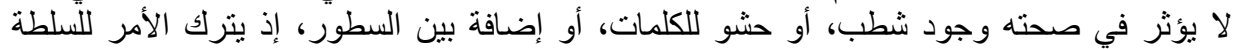

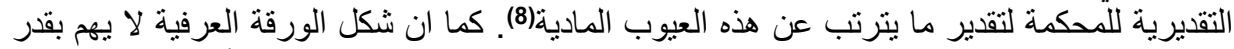

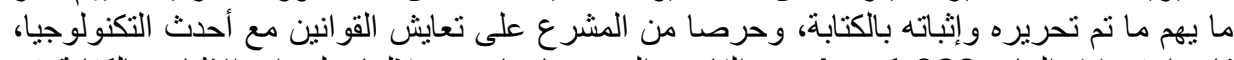

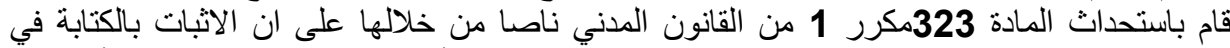

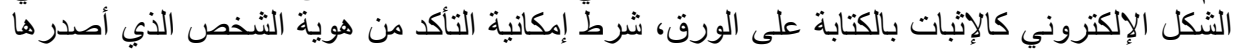

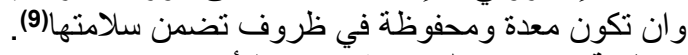

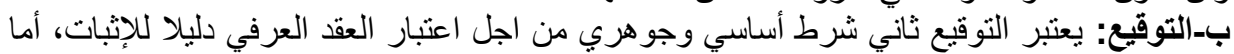

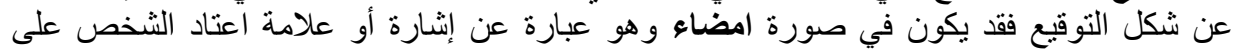

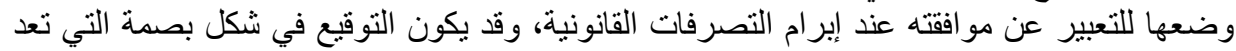

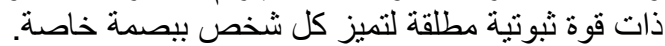

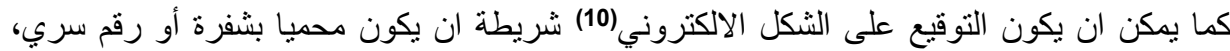

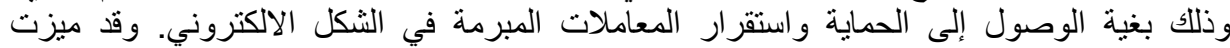

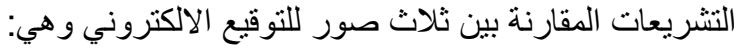
التوقيع الكودي، التوقيع البيو متري، التونئ التوقيع بالقلم الالكتروني.

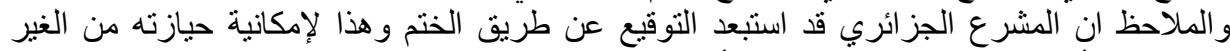

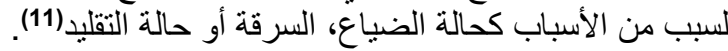

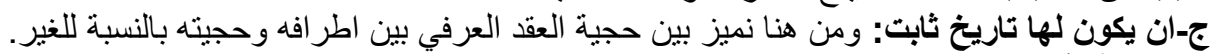

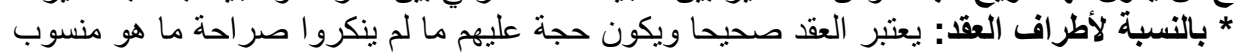

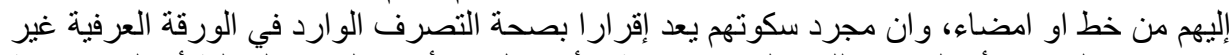

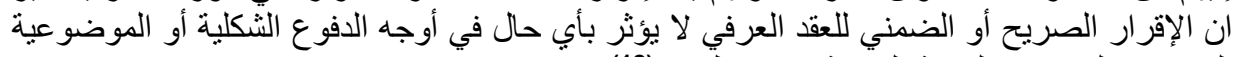

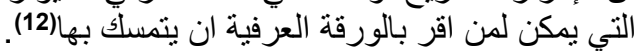
ويلاحظ ان المادة 327 من القانون المدني الجزائري استثتت ورثنة وخلف موقع العقد من الإنكار

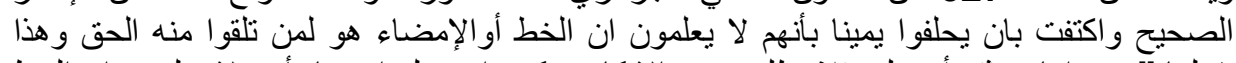

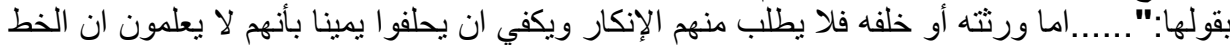

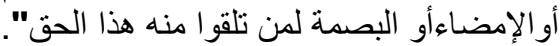

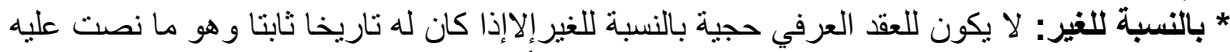

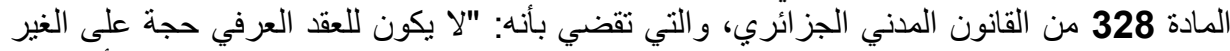
في تاريخه إلا منذ ان يكون له تاريخ ثابت، ويكون له تاريخا ثابتا ابتداء من يوم تسجيله، أو ثبوت النيات 


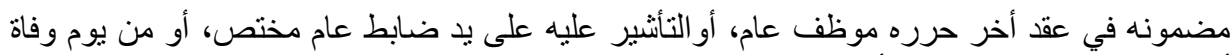

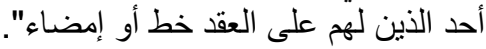

وتجدر الإشارة في هذا المقام الى ان تسجيل العقد العرفي بحسب القرار الصنادر عن المحكمة العليا

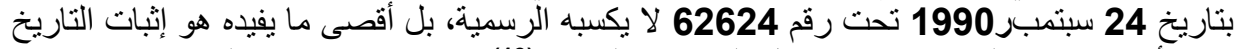

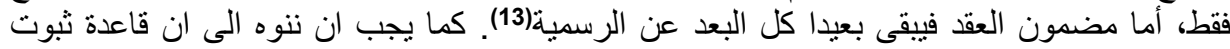

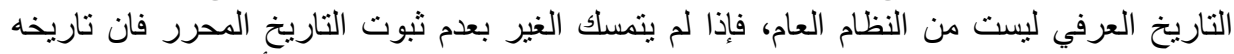

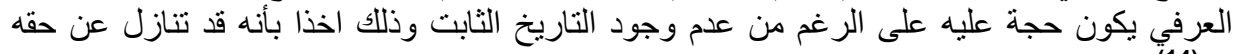

ثانيا-حجية العقود العرفية المتضمنة تصرفا قانونيا

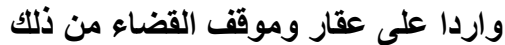

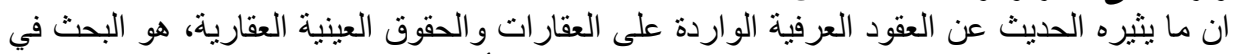

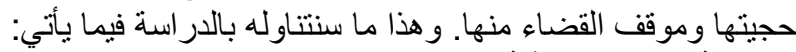

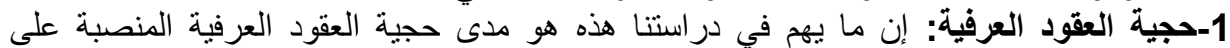

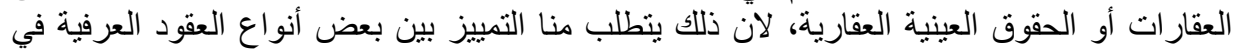

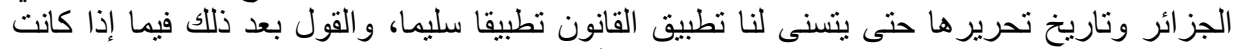

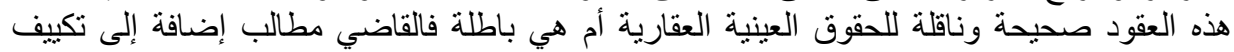

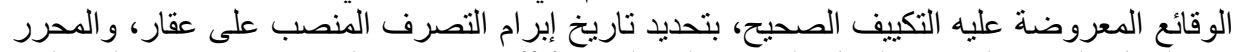

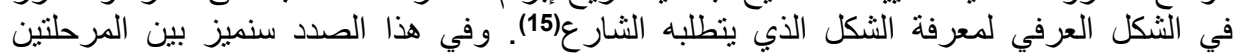

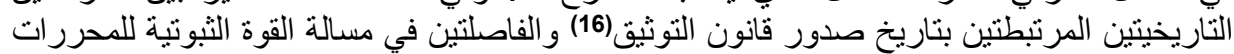

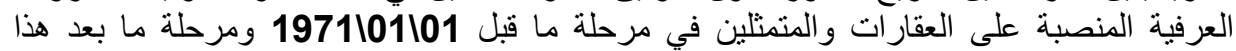
التاريخ، مع التطرق لموقف المحكمة العليا في كلا المرحلتين.

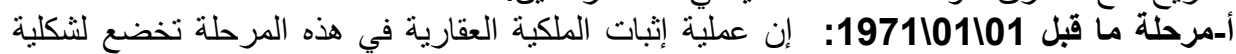

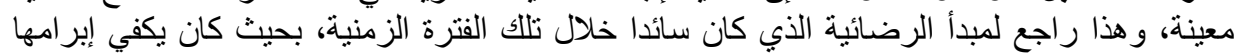

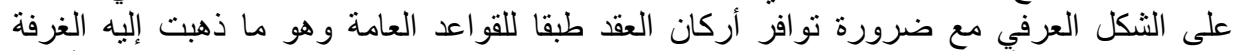

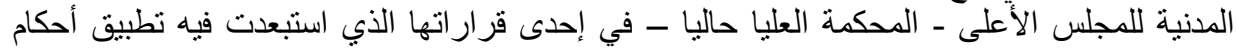

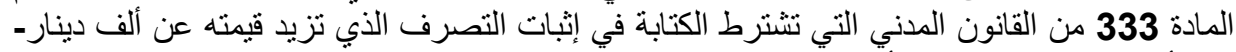

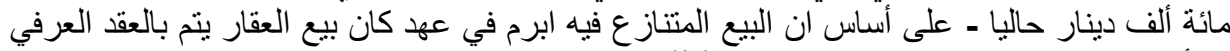

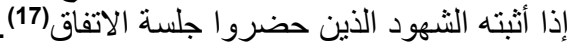

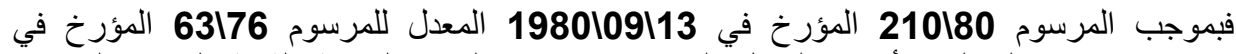

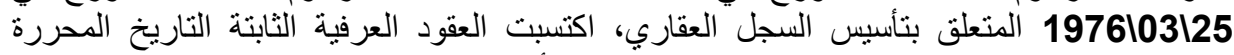

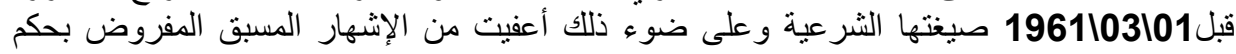
نص المادة 88 من نفس المرسوم.

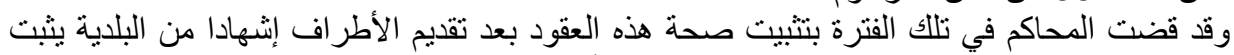

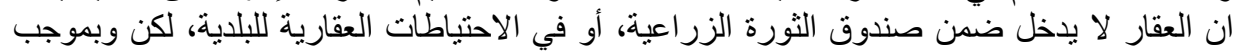

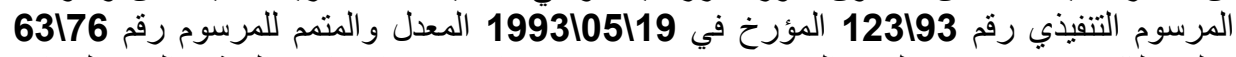

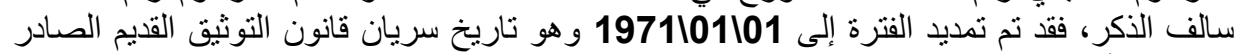

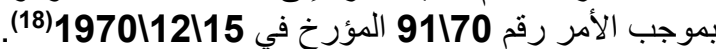

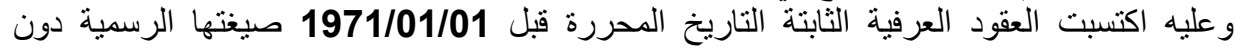

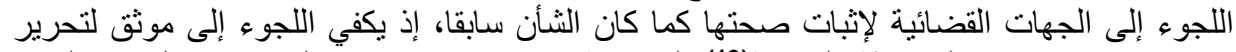

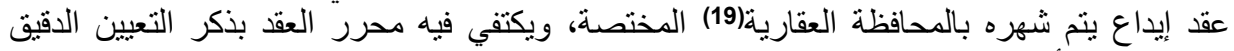
للعقار وكل الأشخاص الدذكورين في العقد العرفي بدون استثناء، وهذا لتسهيل ضبط التهر البطاقة العقارية مع إعفاء المحرر من ذكر أصل الملكية. 


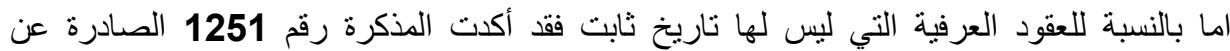

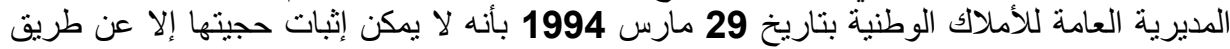

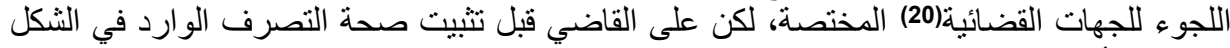

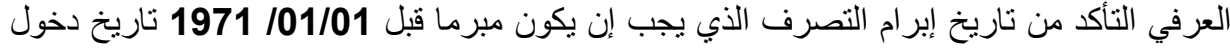
قانون التوثيق حيز التطبيق.

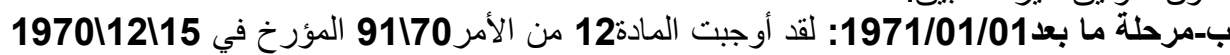

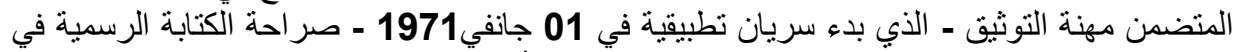

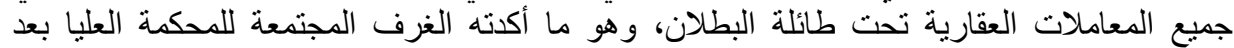

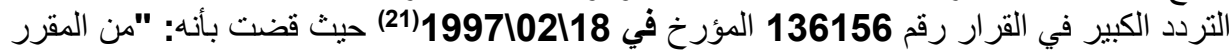

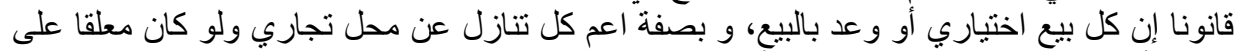

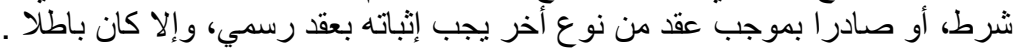

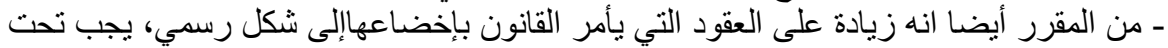

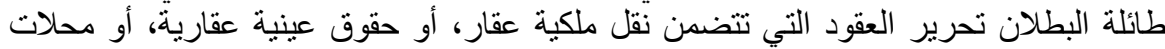

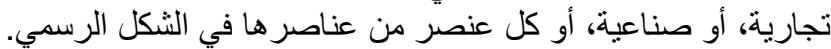
- ومن المقرر أيضا ان يعاد الدتعاقدين إلى الحالة التي كانا عليها قبل العقد في حالة بطلان العقد

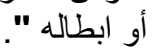

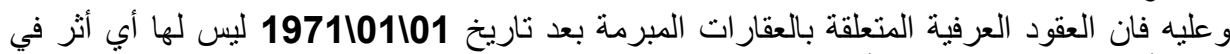

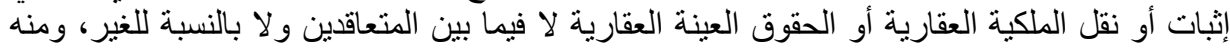

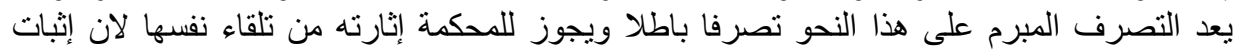

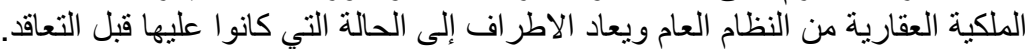

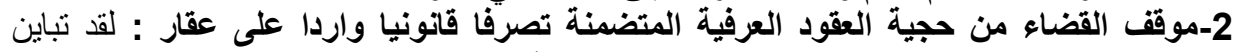

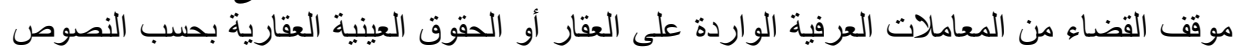

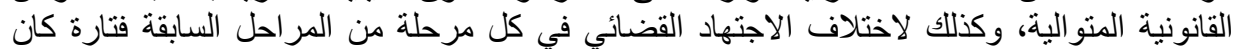

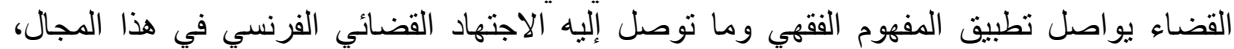

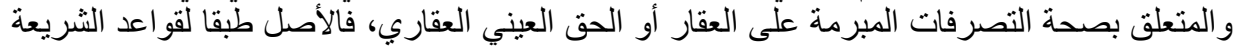

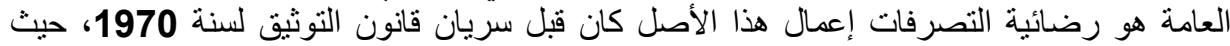

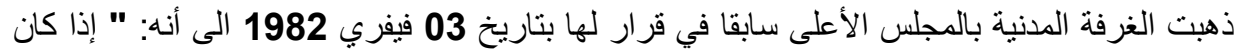

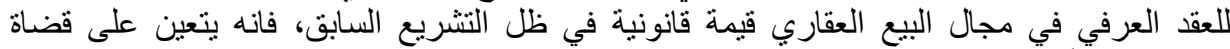

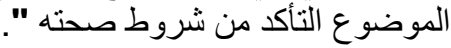

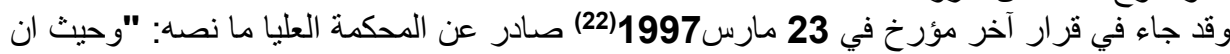

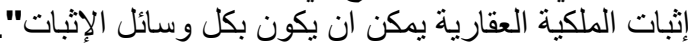

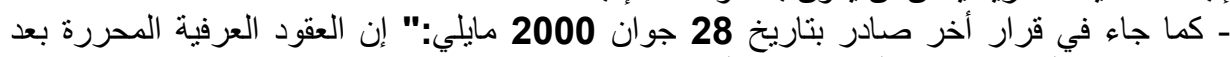
سريان قانون ألتوثيق تعد باطلة بطلانا مطار فيلقا".

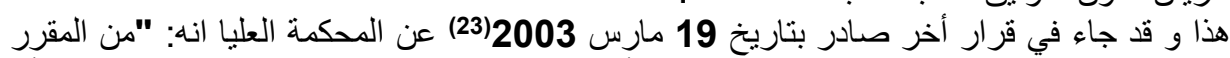

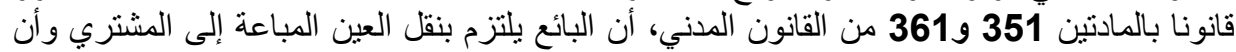

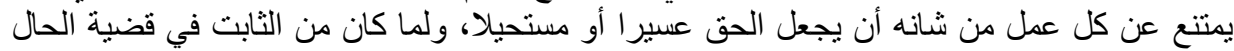

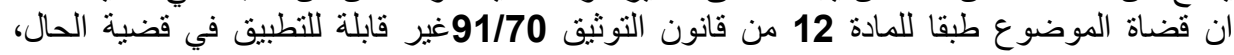

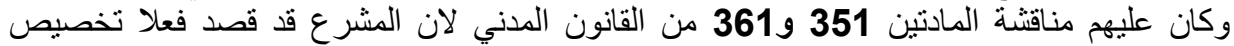

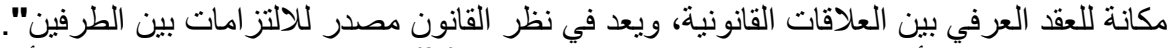

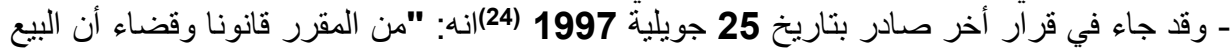

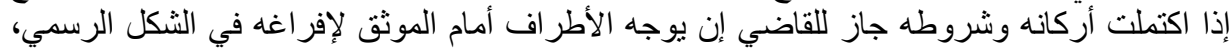

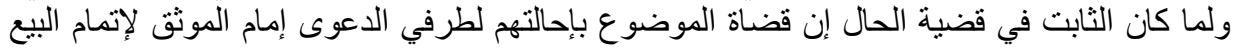




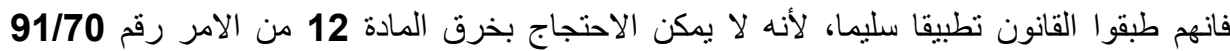

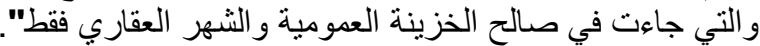

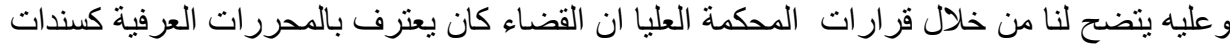

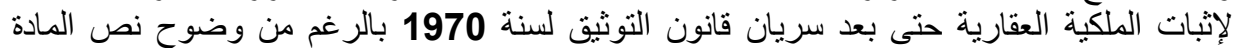

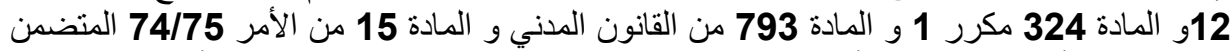

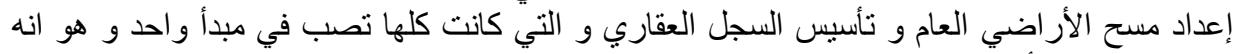

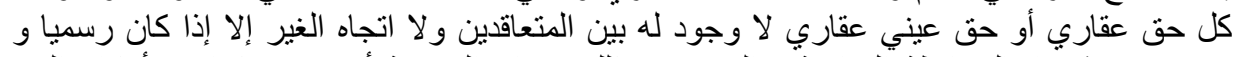

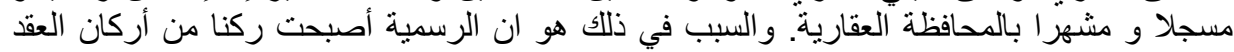

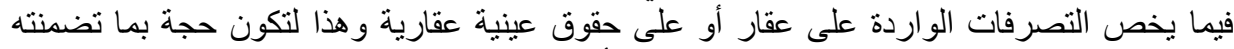

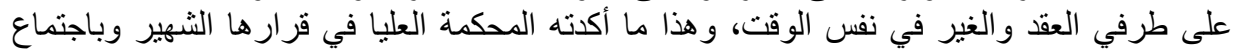

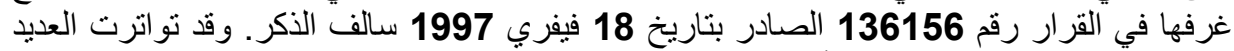
من القر ارات القضائية في هذا الثأن (25).

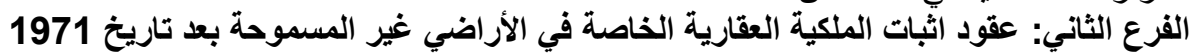

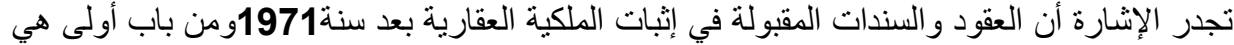

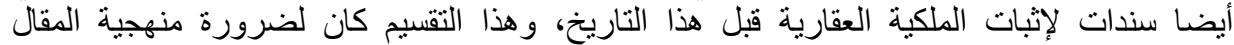

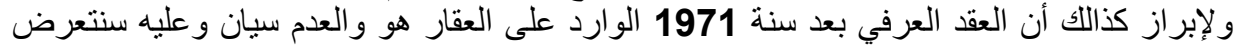
لبيان العقود الرسمية وحجيتها في الإثبات وموقف القئ القضاء من هذه العقود. أولا-مفهوم العقود الرسمية الرئية

لتحديد مفهوم العقد الرسمي لابد من التطرق إلى إلى تعريفه الدقيق بحسب ما جاء في القانون وكذا

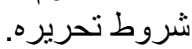

1-تعريف العقد الرسمي: لتعريف العقد الرسمي، نرجع إلى القانون المدني وبالضبط المادة

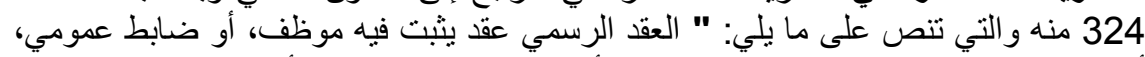

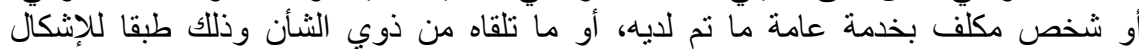

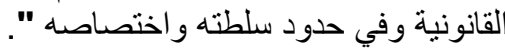

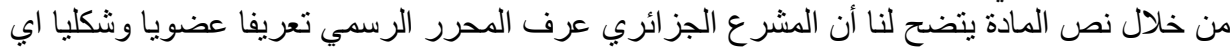

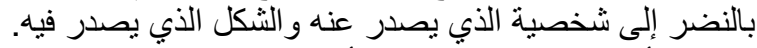

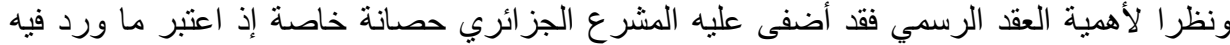

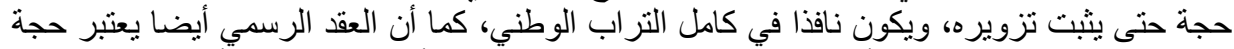

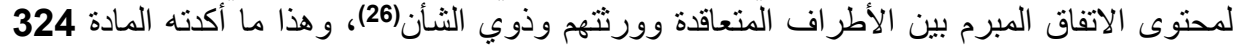
مكرر6 من القانون المدني الجز ائري.

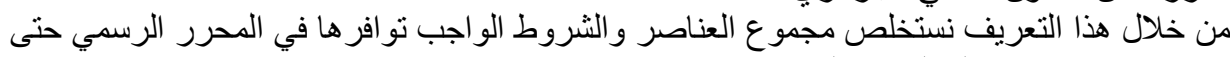

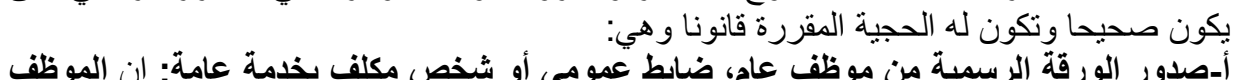

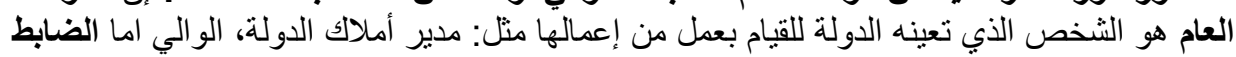

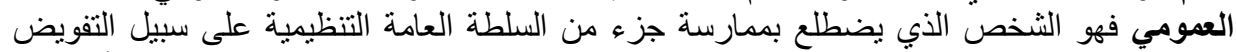

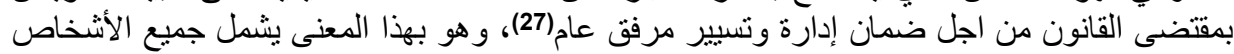

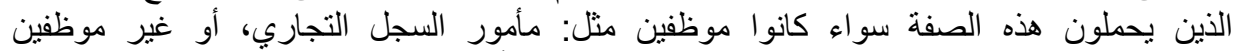

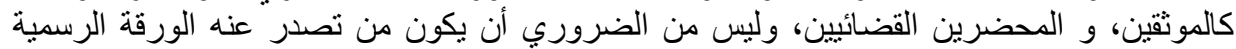

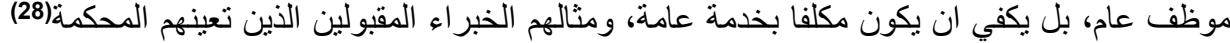

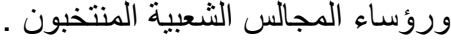


أما بالنسبة للعقود التي كانت تحرر سابقا من قبل القاضي الثر عي فهي تكتسي نفس الطابع الرسمي

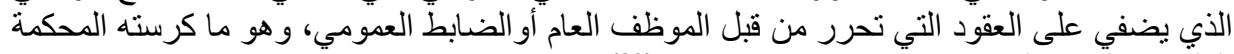

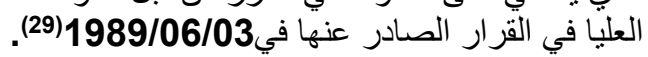

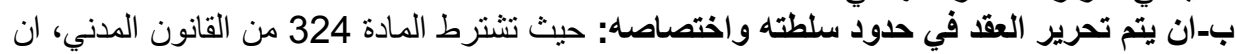

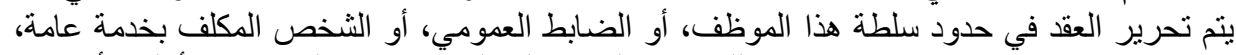

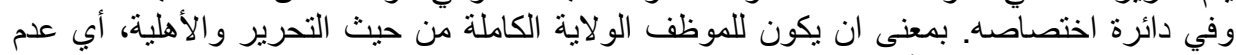

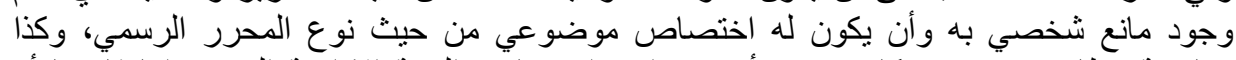

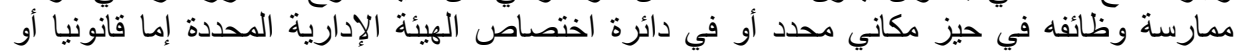

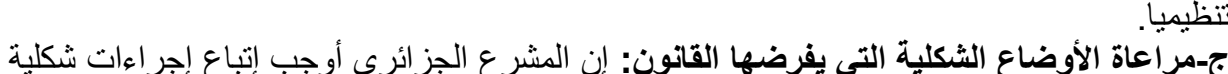

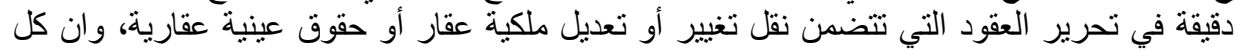
عقد لا بتم وفق الإجر اءات ألمقررة يكون باطنا.

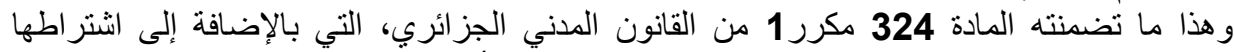

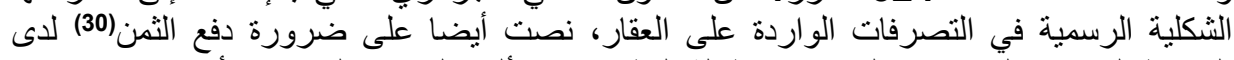

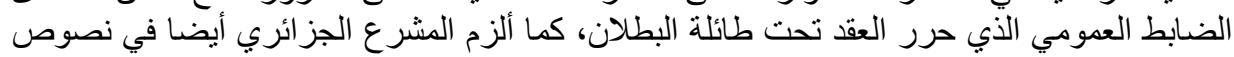

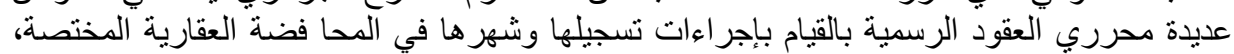

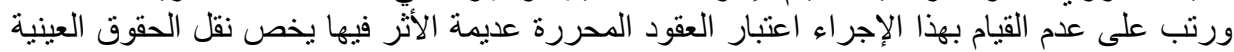
العقارية التي تتضنمنها (31).

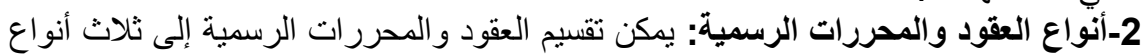

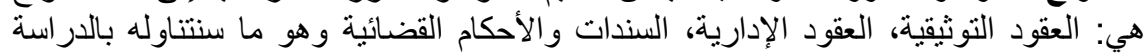
فيمًا بلي: العقد

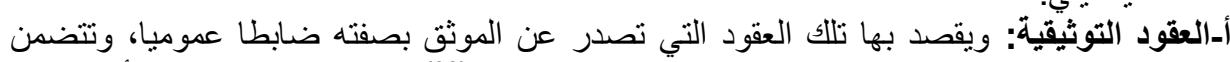

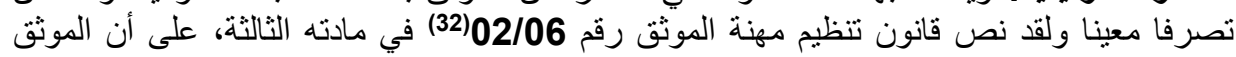

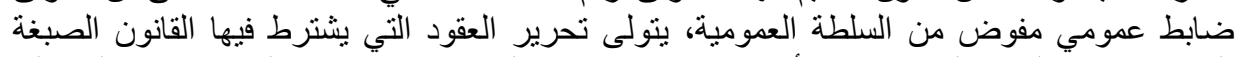

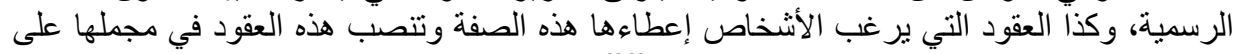

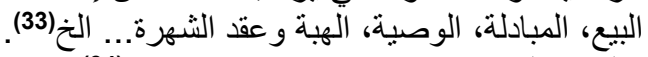

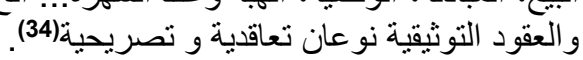

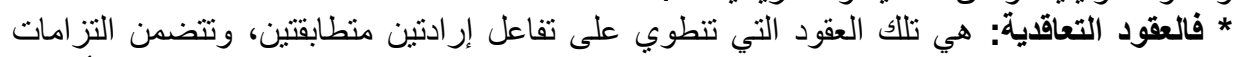

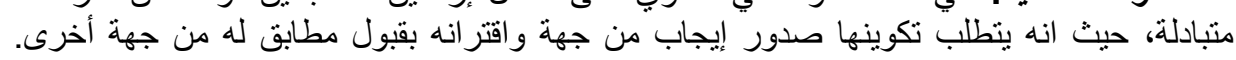
ونذكر منها عقد البيع، عقد المقايضة.

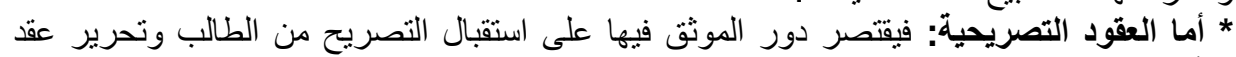

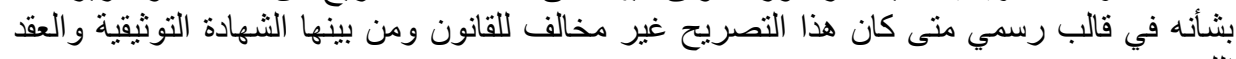
اللفيف.

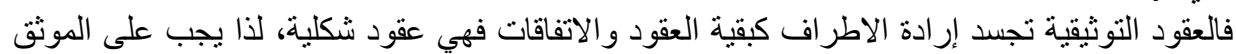

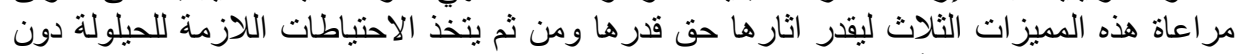

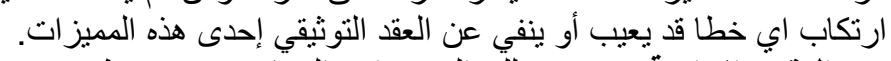

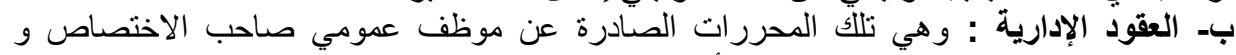

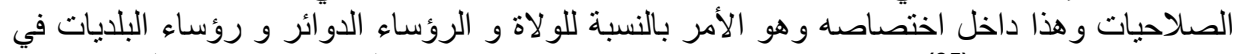

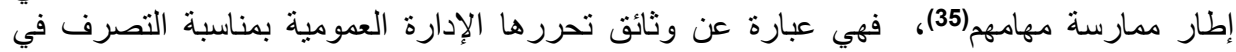

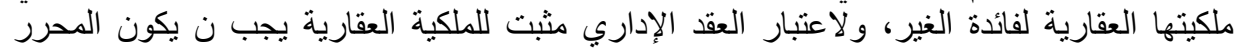

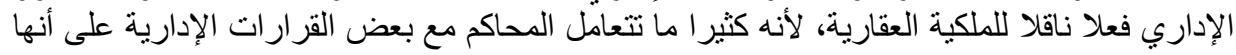




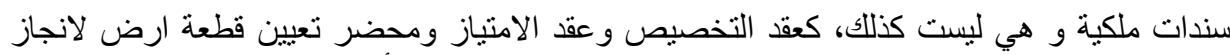

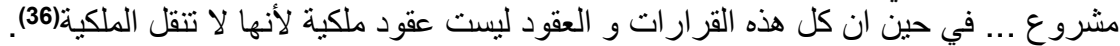

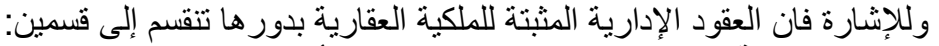

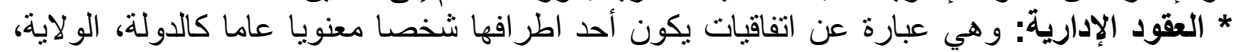

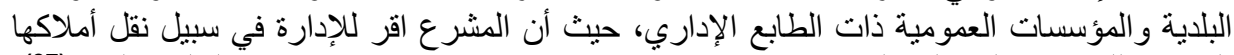

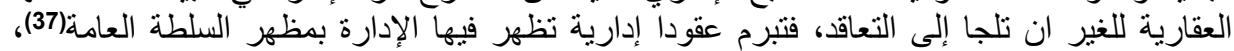

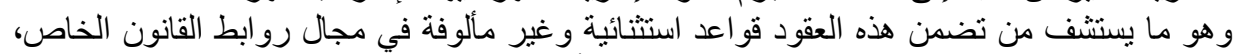

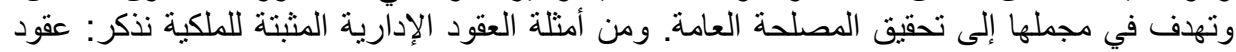
التتازل عن قطع أرضية، العقود الإدارية المعدة من طرف مدرية أملاكل الدالية الدولة المتعلقة باستصلاح الأراضي و عقد البيع الإداري....الخ. الإن.

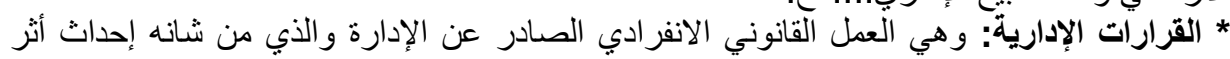

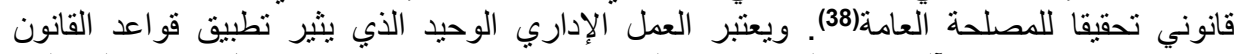

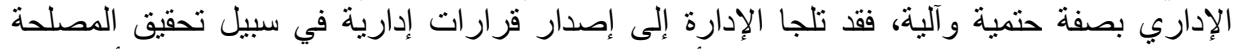

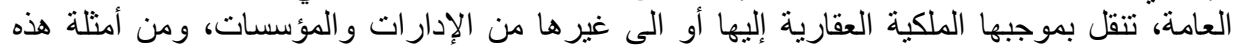

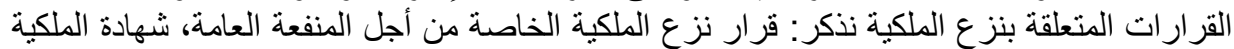

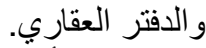

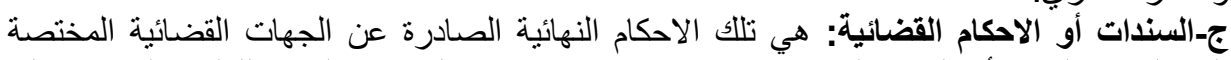

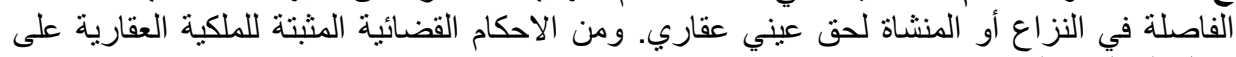

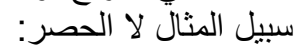

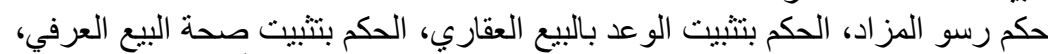

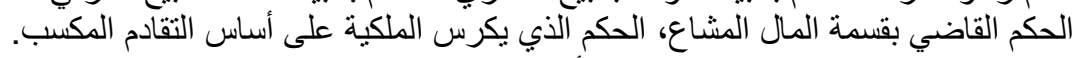
ويشترط المشرع الجزائري لحجية هذه الأحكام ان تسجل بمصالح التسجيل ثم تشهر بالمحافظة العقارية المختصة إقليميا (39).

ثانيا-حجية العقود الرسمية المتضمنة تصرفا قانونيا واردا على عقار وموقف القضاء من ذلكك

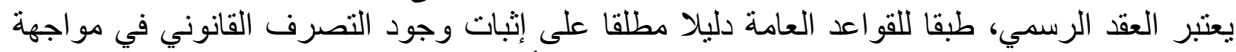

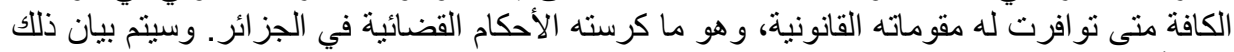

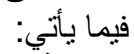
1-حجة العقود الرسمية: طبقا للقواعد العامة المكرسة في القانون المدني، فان العقد الرسمي سواء كان

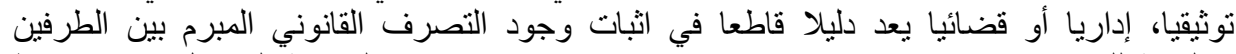

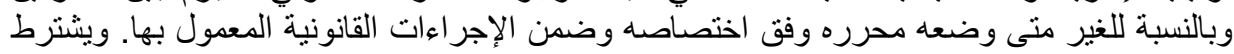

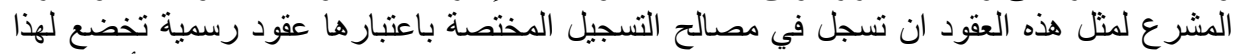

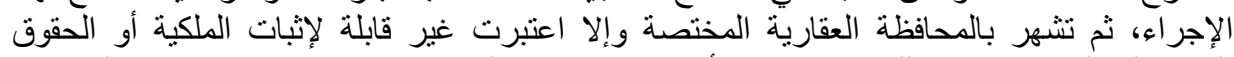

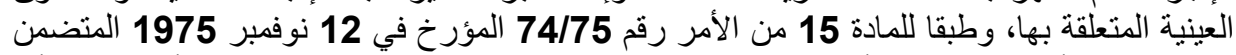

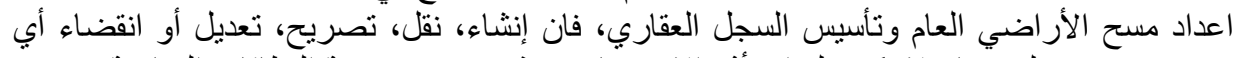

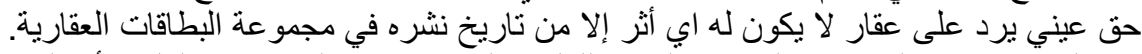

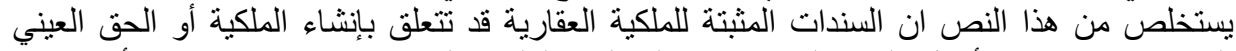

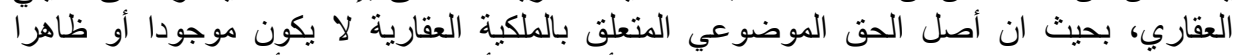

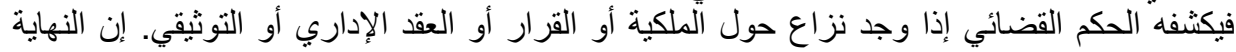

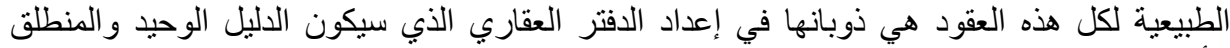

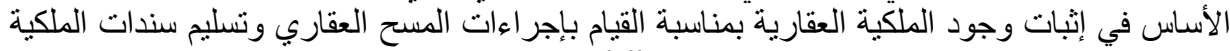

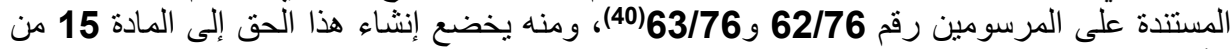
الأمر رقم 74/75 سالف الذكر، ثم يشهر السند ليكون حجة على الغير . 
اما من حيث انتقال الملكية العقارية، فانه لا وجود لتكريس هذا الحق إلا بموجب السند الرسمي طبقا

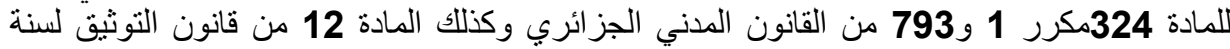

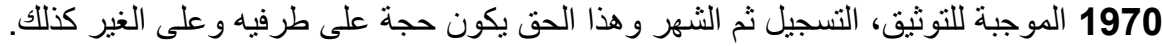

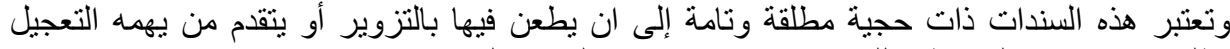
بطلب إيقاف تنفيذ العقد طبقا للمادة 324 مكرر 6 من القان القانون المدني.

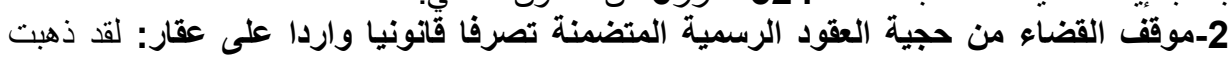

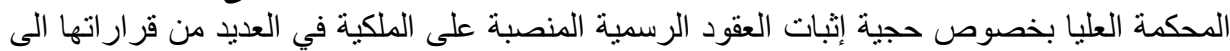
التذكير بحجيتها التامة و المطلقة في ذلك. فبالنسبة للعقود التوثيقية أصدرت المحكمة العليا في 18 نوفمبر 1998(41) قرارا جاء فيه: " ان ان

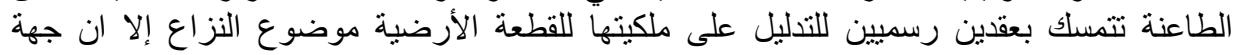

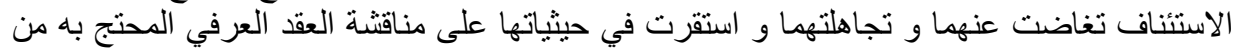

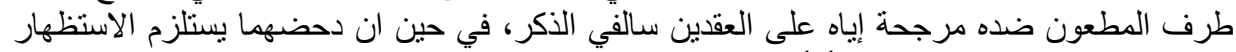

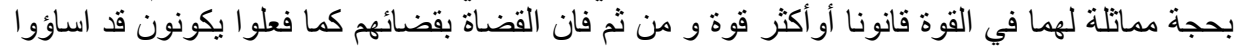

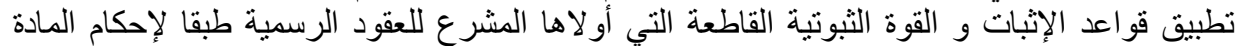
324 مكرر من القانون المدني الجزائري.

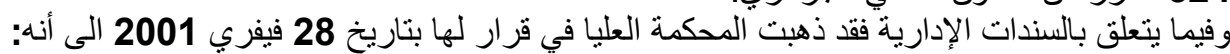

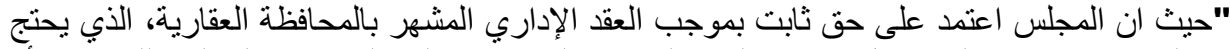

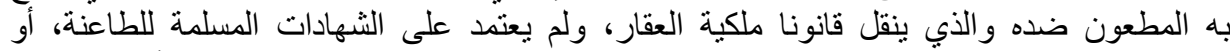
مضر اجتماع مجلس إدارة الوكالة التي لا تعتبر عقد بيع ولا تلتقل ملكية القطعة الأرضية محل لكل

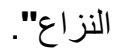
كما ذهبت كذلك في قرارها الصادر بتاريخ 2004/01/21(42) الى أنه: "لا يرقى قرار التخصيص،

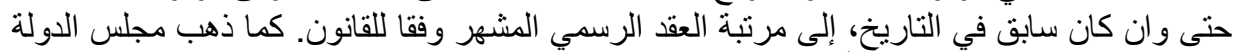

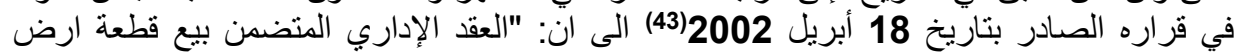

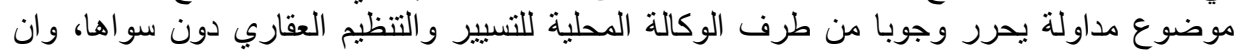

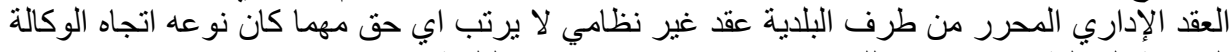

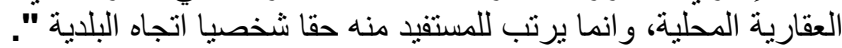

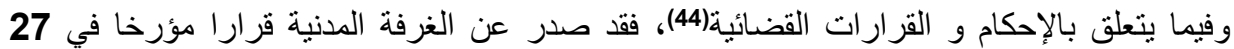

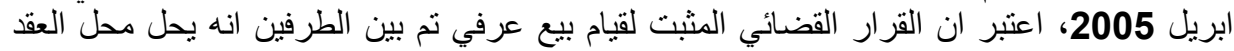

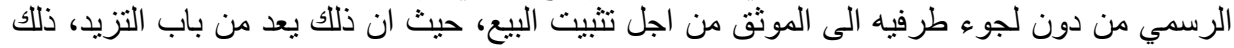

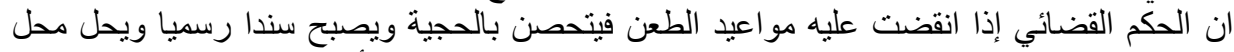

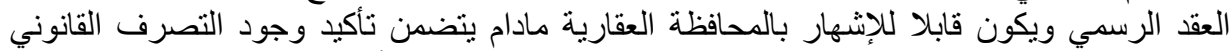

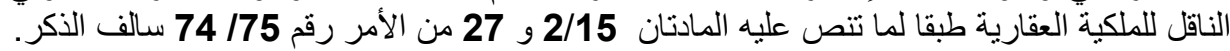

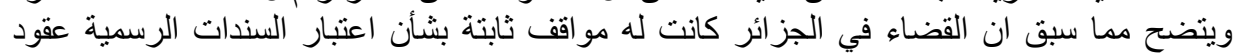
مقبولة لإثبات الملكية العقارية طبقا لما ينص النص كليه القانون. الخاتمة

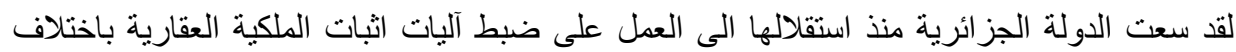
أنو اعها، وذلك بإصدار عدة نصوص تنشريعية وتنظيمية يختلف مضمونها باختلاف الحقبة الزمنية التي لئي صدرت فيها.

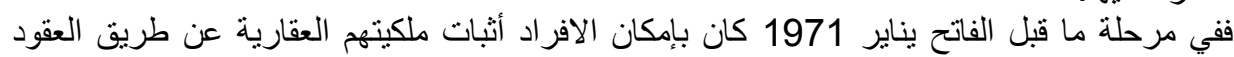

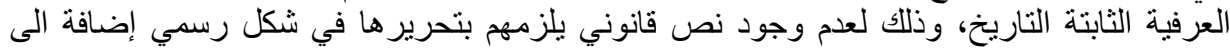

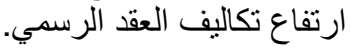




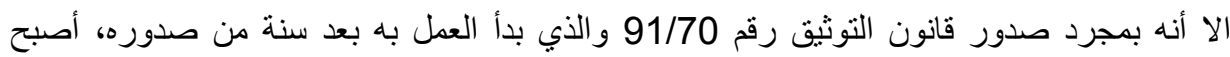

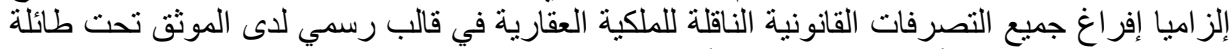

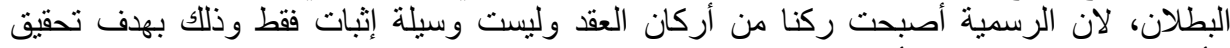

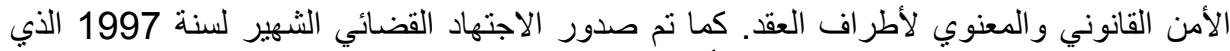

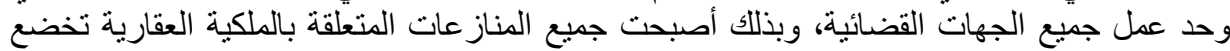

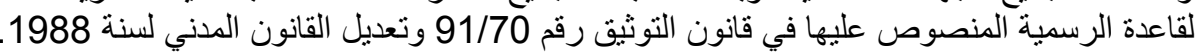

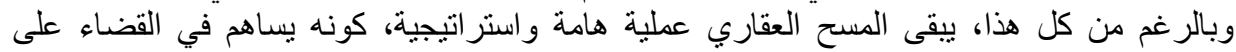

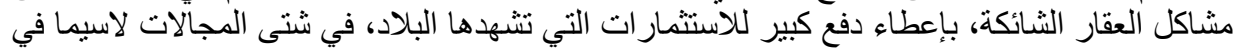

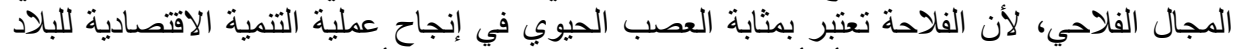

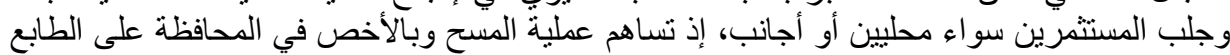

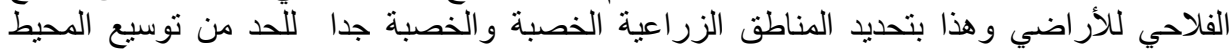

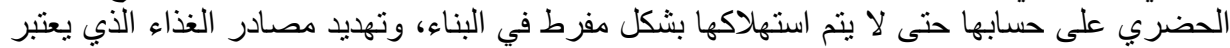
مصدر للضغوطات و التبعة الخارجية.

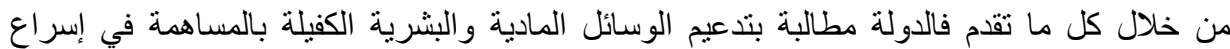

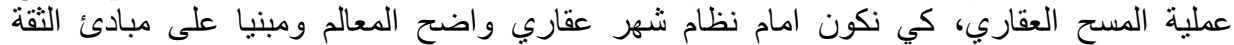

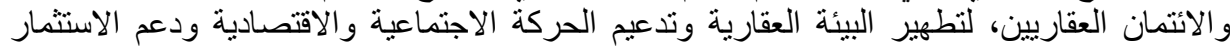
المنتج، وخلق ثروة حقيقية يزدهر بها الاقتصاد الوطني. : التهميش:

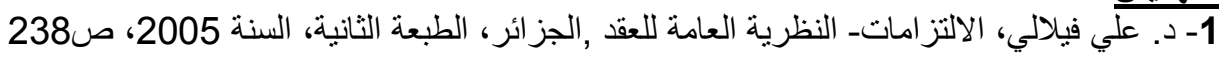

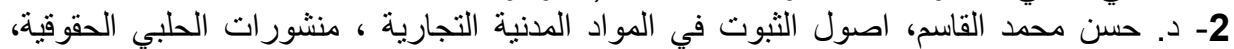

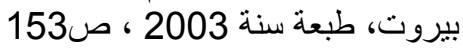
3- د. عجة الجيلالي، مدخل للعلوم القانونيةــ نظرية الحقـ بارتي للنشر، الجزائر، طبعة 2009، ص564 4- د. محمد صبري السعدي، الواضح في الثرح القانون المدني، الاثبات في المو اد المدنية و التجارية

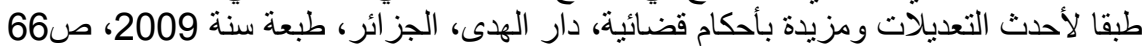

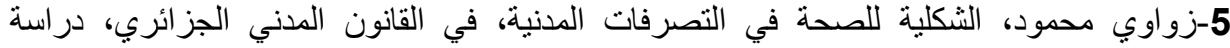

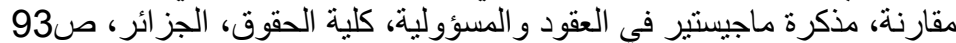

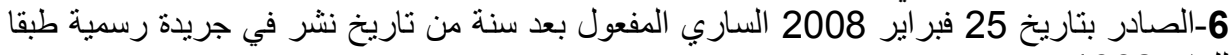

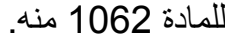
7- مصطفى مجدي هوجة، التنظيم القانوني الجديد لهنازعات الحبازة، دار الفكر العربي، 8-د. محمودي عبد، صالعزيز، العزئ، اليات تطهير الملكية العقارية الخاصة في التشريع الجزائري، مشورات

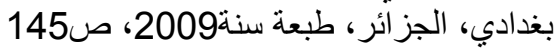
9-تم أستحدانها بموجب طبعة القانون رقم 10105 المؤرخ في 20 يونيو 2005 المعدل والمتمم للقانون 10- انظر المادة327 من الامر58175 المؤرخ في 26سبتمبر 1975 المتضمن ق المدني المعدل و

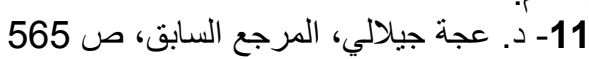
12- مثال :التصسك ببطلان العقد لعدم اتباع الثكلية الرسمية التي تعد ركنا رابعا من اركان العقد

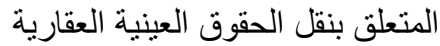
13- حمدي باثشا عمر ، نقل الملكية العقارية، دار هومة، الجزائر ، طبعة .2004 الجقارية 
14- أحمد ابو الوفا، الاثبات في المواد المدنية والتجارية، الدار الجامعية للطباعة والنشر،

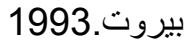

15- قرار رقم 197347 مؤرخ 28 يونيو 2000 ، الغرفة العقارية، "غير منشور" :( من المقرر

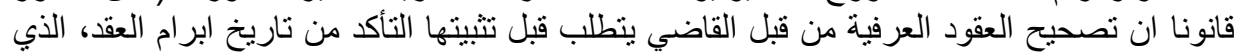

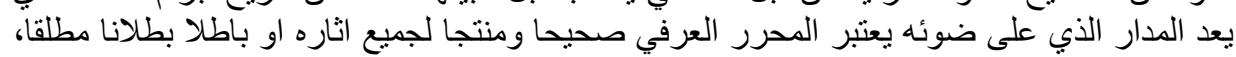

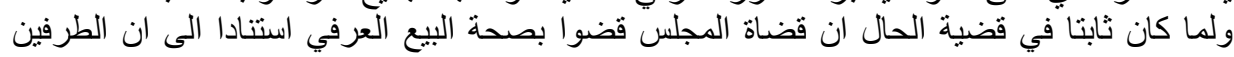

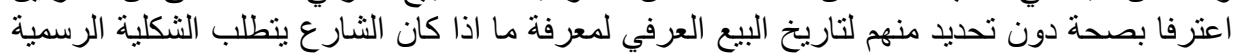

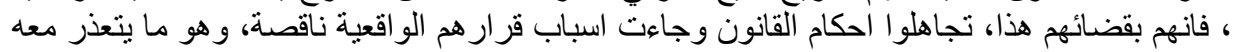

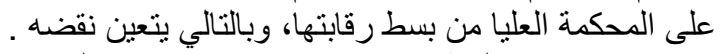

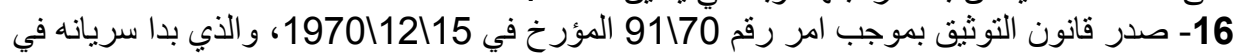

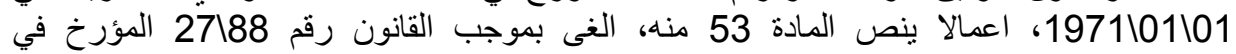

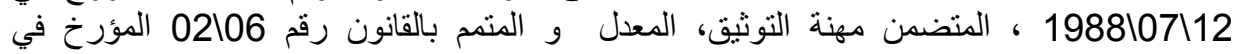
2006/02/20 المتضمن تنظيم مهنة الموثقي .

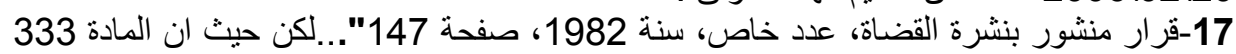

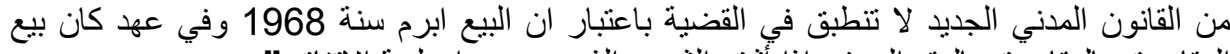

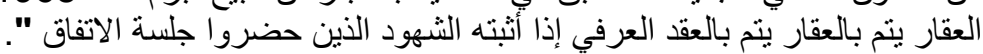

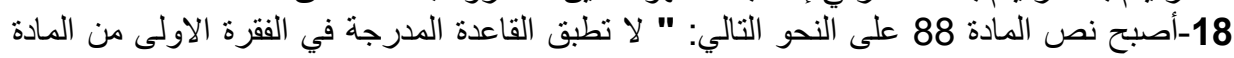

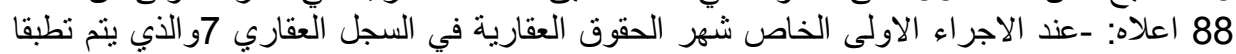

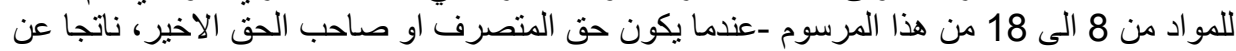

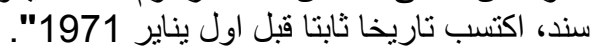

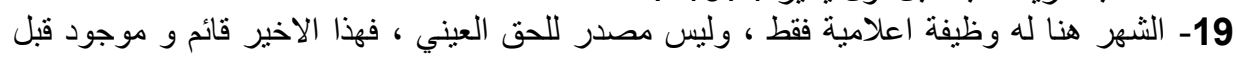

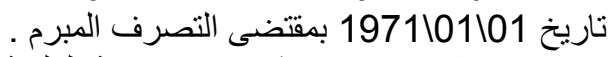
20- راجع كتاب حمدي باثشا عمر - حماية الملكية العقارية الخاصة، دار هومة الجزائر، 2002، ص

60. 59، 58

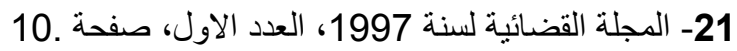

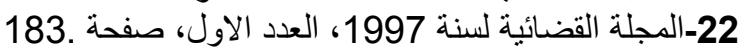

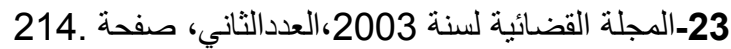

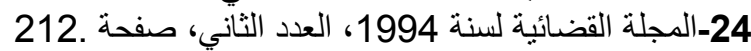
25-قرار مؤرخ في 28 فبراير 1993 تحت رقم 1996 الائ 95606 صادر في المجلة القضائية لسنة 1994،

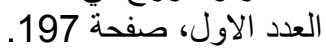

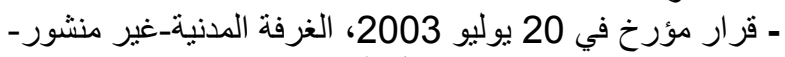

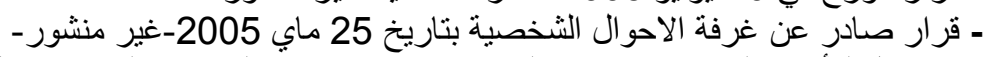

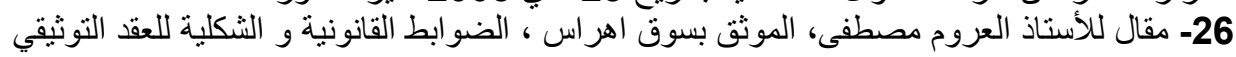

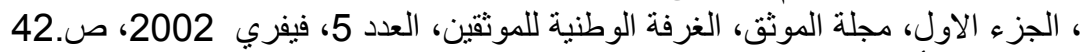

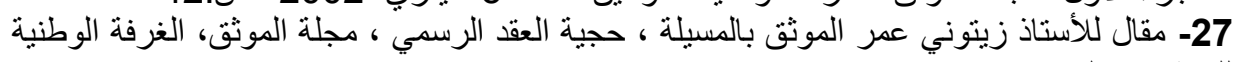

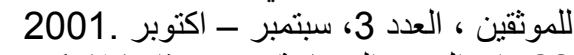

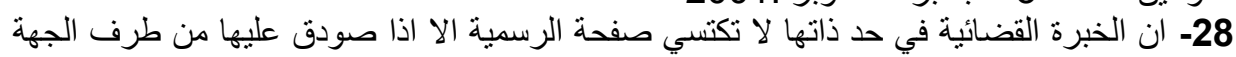

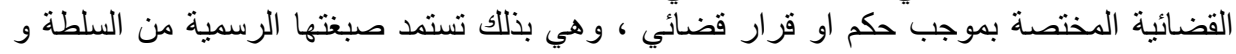

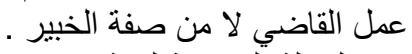

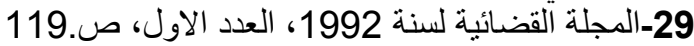

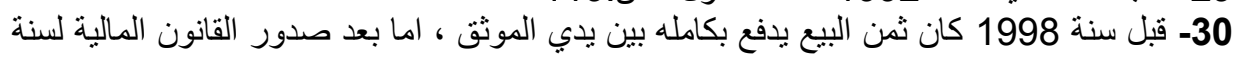

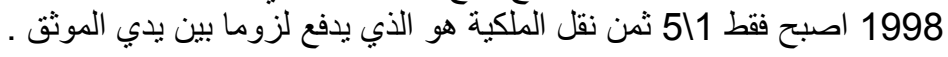




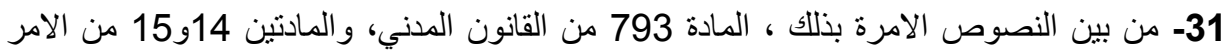

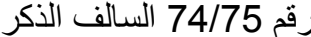

32-القانون رقم 02/06 المؤرخ في 20 فيفري 2006، المتضمن تنظيم مهنة الموثث، الجريدة

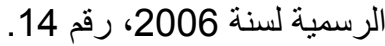

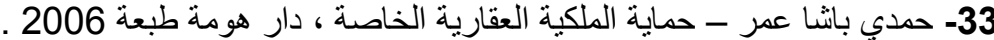

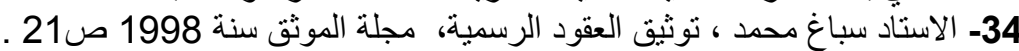

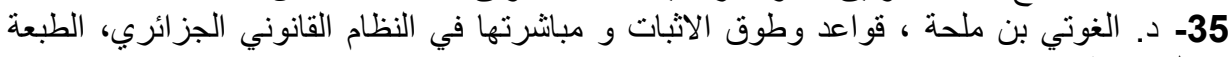

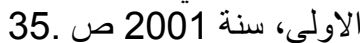

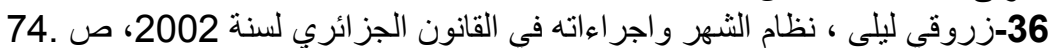

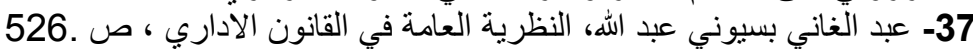

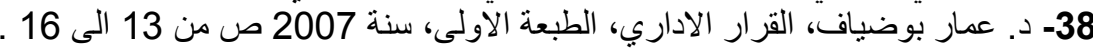

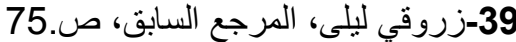

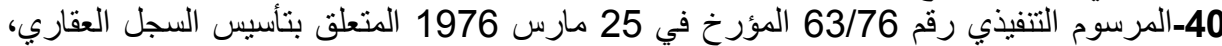

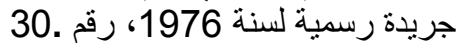

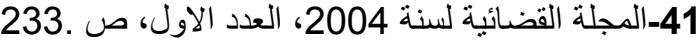

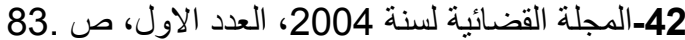

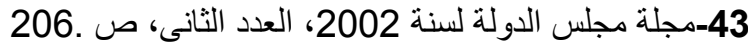

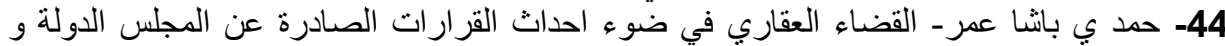
المحكمة العليا ، دار الهومة ، طبعة 2008. 